\title{
Alternativas ao neoliberalismo e o direito à cidade
}

\section{David Harvey}

Para mim, é um imenso prazer estar aqui, mas, em primeiro lugar, eu gostaria de me desculpar por falar em inglês, que é a língua do imperialismo internacional. Espero que o que eu vou dizer seja suficientemente anti-imperialista para que vocês me perdoem por isso.

Eu estou muito grato pelo convite que me fizeram, porque eu aprendo muito com os movimentos sociais. Eu vim aqui para aprender e para ouvir; portanto, já considero esta uma grande experiência educacional, pois, como disse Karl Marx certa vez, é preciso sempre questionar quem vai educar os educadores.

Tenho trabalhado, já há algum tempo, com a idéia de um direito à cidade. Entendo que o direito à cidade significa o direito que todos nós temos de criar cidades que satisfaçam as necessidades humanas, as nossas necessidades. O direito à cidade não é o direito de ter - e eu vou usar uma expressão do inglês - as migalhas que caem da mesa dos ricos. Todos devemos ter os mesmos direitos de construir os diferentes tipos de cidades que nós queremos que existam.

O direito à cidade não é simplesmente o direito ao que já existe na cidade, mas é o direito de transformar a cidade em algo radicalmente diferente. Quando olho para a história, vejo que as cidades foram regidas pelo capital, mais do que pelas pessoas. Assim, nessa luta pelo direito à cidade, haverá também uma luta contra o capital.

Para falar um pouco sobre a história da relação entre o capital e a construção de cidades, começo por uma pergunta. Por que o capital consegue exercer

David Harvey - é geógrafo e um dos principais teóricos urbanos dos últimos 50 anos. Atualmente ensina na City University de Nova Iorque. Escreveu as obras "Explanação na Geografia” em 1969, “O Capital” de Marx,”Justiça Social e a Cidade” (1973). Nas últimas 3 décadas dedicou-se à análise do capitalismo "financeiro", e publicou recentemente "Uma Breve História do Neoliberalismo". 
David Harvey

tantos direitos sobre a cidade? E por que as forças populares são relativamente fracas contra esse poder? Gostaria de lembrar também que, na verdade, a forma como o capital opera nas cidades é uma de suas fraquezas. Por isso, creio que a luta pelo direito à cidade está no centro da luta contra o capital. Estamos vivendo agora, como todos sabem, uma crise financeira do capitalismo. Se examinarmos a história recente, descobriremos que, ao longo dos últimos 30 anos, houve muitas crises financeiras. Alguém fez os cálculos e disse que, desde 1970, houve 378 crises financeiras no mundo. Entre 1945 e 1970, houve apenas 56 crises financeiras. Portanto, o capital tem produzido muitas crises financeiras nos últimos 30 ou 40 anos. É interessante observar que muitas dessas crises financeiras têm origem na urbanização. No fim da década de 80 do século XX, a economia japonesa quebrou, e quebrou por conta da especulação da propriedade e da terra. Em 1987, nos Estados Unidos, houve uma enorme crise, na qual centenas de bancos foram à falência, e tudo se deveu à especulação sobre a habitação e o desenvolvimento de propriedade imobiliária. Nos anos 70 , houve uma grande crise mundial nos mercados imobiliários. Eu poderia continuar indefinidamente, dando-lhes exemplos de crises financeiras com origens urbanas. Segundo meu cálculo, metade das crises financeiras dos últimos 30 anos teve origem na propriedade urbana. A recente crise nos Estados Unidos deve-se a algo chamado "crise das hipotecas subprime". Em minha opinião, essa crise não é a crise das hipotecas subprime, trata-se, antes, de uma crise urbana.

O que aconteceu foi que, nos anos de 90, surgiu o problema de um excedente de dinheiro sem destinação - o capitalismo é um sistema que sempre produz excedentes. Podemos analisar isso da seguinte forma: o capitalismo acorda certa manhã e vai ao mercado com certa quantidade de dinheiro; compra trabalho e meios de produção; põe esses elementos para trabalhar e produz certo bem, para vendê-lo por mais dinheiro; no fim do dia, o capitalista tem mais dinheiro do que tinha no começo do dia. Pergunto: o que ele faz com aquele extra que conseguiu? Se ele fosse como vocês e eu, provavelmente sairia e divertir-se-ia gastando o dinheiro. Mas o capitalismo não é assim. Há forças competitivas que impelem o capitalista a reinvestir parte de seu capital em novos desenvolvimentos. $\mathrm{Na}$ história do capitalismo, tem havido uma taxa de crescimento de 3\% desde 1750. Uma taxa de crescimento de 3\% significa que é preciso encontrar saídas para o capital. Desse modo, o capitalismo sempre se confronta com aquilo que eu chamo "problema da absorção do excedente do capital": onde eu posso encontrar uma saída lucrativa para aplicar o meu capital? Em 1750, o mundo inteiro estava aberto para essa questão. Naquela época, o valor total da economia global era de 135 bilhões de dólares em bens e serviços. Em 1950, há 4 trilhões de dólares em 
circulação, e é preciso encontrar saídas para 3\% de 4 trilhões. Em 2000, são 42 trilhões de dólares em circulação. Hoje, provavelmente, esse valor chega a cerca de 50 trilhões. Em 25 anos, a uma taxa de crescimento de 3\%, ele será de 100 trilhões. Isso significa que há uma crescente dificuldade em encontrar saídas rentáveis para o excedente de capital.

Essa situação pode ser apresentada de outra forma. Quando o capitalismo resumia-se essencialmente ao que acontecia em Manchester e em outros poucos lugares do mundo, uma taxa de crescimento de 3\% não representava um problema. Atualmente temos de colocar uma taxa de 3\% em tudo o que acontece na China, no Leste e no Sudeste asiáticos, na Europa, em grande parte da América Latina e na América do Norte. Daí um imenso, um gigantesco problema. Os capitalistas, quando têm dinheiro, têm também a escolha de como reinvesti-lo. Você pode investir em nova produção. Um dos argumentos para tornar os ricos ainda mais ricos é que eles reinvestirão na produção, o que gerará mais emprego e melhores condições de vida para o povo. Mas, desde 1970, eles têm investido cada vez menos em novas produções. Eles têm investido na compra de ativos, ações, direitos de propriedade, inclusive intelectual, e, é claro, em propriedade imobiliária. Portanto, desde 1970, cada vez mais dinheiro tem sido destinado a ativos financeiros, e, quando a classe capitalista começa a comprar ativos, o valor deles aumenta. Assim, começam os capitalistas a fazer dinheiro com o aumento do valor de seus ativos. Com isso, os preços da propriedade imobiliária elevam-se mais e mais. Isso não torna uma cidade melhor, torna-a, antes, mais cara. Além disso, para construir condomínios de luxo e casas exclusivas, os capitalistas têm de empurrar os pobres para fora de suas terras -têm de tirar o nosso direito à cidade. Em Nova York, acho muito difícil viver em Manhattan, e eu sou um professor universitário razoavelmente bem pago. A massa da população que, de fato, trabalha na cidade não tem condições de viver na cidade porque o preço dos imóveis subiu exageradamente. Em outras palavras, o direito das pessoas à cidade foi subtraído. Às vezes, ele é subtraído por meio de ações do Mercado, às vezes, por meio de ações do governo, que expulsa as pessoas de onde elas vivem, às vezes, ele é subtraído por meios ilegais, violentos, ateando-se fogo a um prédio. Houve um período em que parte de Nova York sofreu incêndio após incêndio.

A consequência de tudo isso é a criação de uma situação em que os ricos podem cada vez mais exercer seu domínio sobre toda a cidade. Aliás, eles têm de fazer isso, porque essa é a única forma de usar seu excedente de capital. Em algum momento, entretanto, há também incentivos para que esse processo de construção da cidade alcance as pessoas mais pobres. As instituições financeiras concedem empréstimos aos empreendedores imobiliários para que desenvolvam grandes áreas 
David Harvey

da cidade. Mas, se os empreendedores promovem o desenvolvimento, o problema é: para quem eles vendem os imóveis? Se a renda da classe trabalhadora estivesse crescendo, os imóveis poderiam ser vendidos aos trabalhadores. Desde os anos 70 , porém, as políticas do neoliberalismo têm implicado reduções salariais. Nos Estados Unidos, os salários reais não têm aumentado desde 1970, de tal modo que os salários reais são constantes, mas os preços dos imóveis estão subindo. Ora, de onde vem a demanda por habitação? A resposta consistia em conduzir as classes trabalhadoras a uma situação de débito. Constatamos, assim, que o débito com habitação nos Estados Unidos passou de cerca de 40.000 dólares por família para mais de 120.000 dólares por família nos últimos 20 anos. As instituições financeiras batem nas portas dos trabalhadores e dizem "Nós temos um bom negócio para você. Nós lhe emprestamos dinheiro e você pode ter sua casa própria. Não se preocupe, pois, se mais adiante, você não conseguir pagar sua dívida, porque os preços dos imóveis estão subindo, tudo estará bem".

Desse modo, mais e mais pessoas de baixa renda foram levadas a contrair dívidas. Mas, há cerca de dois anos, os preços dos imóveis começaram a cair. A distância entre o que os trabalhadores podiam pagar e o tamanho da dívida tornou-se grande demais. De repente houve uma onda de execuções de hipotecas em muitas cidades americanas. Como geralmente acontece com algo desse tipo, observa-se um desenvolvimento geográfico desigual em tal onda. A primeira onda atingiu comunidades de baixíssima renda em muitas das cidades mais antigas dos Estados Unidos. Há um maravilhoso mapa que pode ser visto na página eletrônica da BBC das execuções hipotecárias na cidade de Cleveland. O que se vê é um mapa pontilhado das execuções, que é altamente concentrado em certas áreas da cidade. Do lado desse mapa, um outro mostra a distribuição da população afro-americana, e os dois mapas correspondem-se entre si. Isso demonstra que a população afro-americana de baixa renda sofreu um roubo. Foi a maior perda de ativos de populações de baixa renda nos Estados Unidos de todos os tempos: dois milhões de pessoas perderam suas casas. Naquele mesmo momento, o pagamento de bônus em Wall Street ultrapassava a casa dos 30 bilhões de dólares - que é o dinheiro extra pago aos banqueiros pelo seu trabalho. Assim, os 30 bilhões pagos em Wall Street foram efetivamente retirados das populações dos bairros de baixa renda. Refere-se a isso nos Estados Unidos como um "Katrina financeiro", porque, como todos lembram, o furacão Katrina atingiu particularmente Nova Orleans, e foi a população negra de baixa renda que foi deixada para trás, muitos tendo morrido. Os ricos protegeram seu direito à cidade, mas os pobres essencialmente perderam o seu.

Na Flórida, na Califórnia e no Sudoeste americano, o padrão foi diferente. 
Foram muito mais atingidas as periferias das cidades. Lá, muito dinheiro estava sendo emprestado a grupos de construtoras e incorporadoras. Eles estavam construindo casas fora da cidade, a $45 \mathrm{~km}$ de Tuscon e de Los Angeles, e não conseguiam encontrar compradores. Buscaram, então, a população branca que não gostava de viver perto de imigrantes e de negros nas cidades centrais. Isso levou a uma situação que se revelou há um ano, quando os altos preços da gasolina tornaram as coisas muito difíceis para aquelas comunidades. Muitas pessoas não conseguiam pagar suas dívidas, de modo que uma onda de execuções hipotecárias atingiu os subúrbios, e principalmente os brancos, em lugares como a Flórida, o Arizona e a Califórnia. Enquanto isso, Wall Street pegou todas aquelas hipotecas de risco e embrulhou-as em estranhos instrumentos financeiros. Todas as hipotecas de um determinado lugar eram colocadas em um pacote, e partes daquele pacote era vendida a outras pessoas. Como resultado, todo o mercado financeiro de hipotecas globalizou-se. Assim, pedaços de propriedade hipotecária foram vendidas a pessoas na Noruega, na Alemanha, no Golfo e em qualquer lugar. Todos foram convencidos de que essas hipotecas e esses instrumentos financeiros eram tão seguros quanto casas. Na realidade, não se mostraram seguros, e então sobreveio a grande crise, que segue sem parar. Meu argumento é: se essa crise é basicamente uma crise de urbanização, a solução deve ser uma urbanização diferente. Por isso, a luta pelo direito à cidade torna-se crucial - porque nós temos a oportunidade de fazer algo diferente.

Sempre me perguntam se essa crise é o fim do neoliberalismo. Minha resposta é "não", quando se olha para o que está sendo proposto em Washington e em Londres. De acordo com um dos princípios básicos estabelecidos na década de 70, o poder do Estado deve proteger as instituições financeiras a qualquer preço. Se há um conflito entre o bem-estar das instituições financeiras e o bem-estar do povo, opta-se pelo bem-estar das instituições financeiras. Esse princípio foi desenvolvido na cidade de Nova York City em meados dos anos 70 e foi definido internacionalmente pela primeira vez quando houve a ameaça de falência do México em 1982. Se o México tivesse ido à falência, isso teria destruído os bancos de investimentos de Nova York. Assim, o Banco Central dos Estados Unidos e o Fundo Monetário Internacional (FMI) combinaram esforços para ajudar o México a não entrar em falência. Em outras palavras, eles emprestaram o dinheiro de que o México precisava para pagar os banqueiros de Nova York. Mas, ao fazê-lo, impuseram austeridade à população mexicana. Ou seja: protegeram os bancos e destruíram as pessoas. Essa tem sido a prática padrão do FMI desde então. Por outro lado, se examinarmos a resposta dada à crise pelos Estados Unidos e pela Inglaterra, veremos que o que eles efetivamente fizeram foi salvar os bancos - 
David Harvey

são 700 bilhões de dólares para os bancos nos Estados Unidos. Eles não fizeram absolutamente nada para proteger os proprietários de imóveis que perderam suas casas. Logo, é exatamente o mesmo princípio que agora está sendo aplicado: proteger as instituições financeiras e desprezar o povo. Deveríamos ter usado os 700 bilhões para criar um banco de redesenvolvimento urbano, para salvar todas as comunidades que estavam sendo destruídas e reconstruir as cidades a partir das demandas populares. É interessante constatar que, se isso tivesse sido feito antes, grande parte da crise teria simplesmente desaparecido, porque não haveria a execução das hipotecas. Nesse meio tempo, precisamos organizar um movimento antidespejo - e temos visto isso acontecer em Boston e em algumas outras cidades. Mas, neste momento da história dos Estados Unidos, há um sentimento de que a mobilização popular está restrita, porque a eleição de Obama é a prioridade. Muitas pessoas esperam que Obama faça algo diferente. Infelizmente, seus consultores econômicos são exatamente os mesmos que criaram o problema. Duvido que Obama venha a ser tão progressista quanto Lula. Acredito que teremos de esperar um pouco antes que os movimentos sociais comecem a agir. Precisamos de um movimento nacional pela reforma urbana, como o que este Fórum. Temos de construir uma militância do mesmo tipo da que vocês construíram aqui. Temos de começar a exercer, de fato, nosso direito à cidade. Em algum momento, teremos de reverter o modo como as instituições financeiras são priorizadas em detrimento do povo. Temos de questionar o que é mais importante - o valor dos bancos ou o valor da humanidade. $\mathrm{O}$ sistema bancário deveria servir às pessoas, e não viver à custa das pessoas. Para que nos tornemos capazes de exercer nosso direito à cidade, a única forma é, em algum momento, controlar o problema da absorção do excedente capitalista. Temos de socializar o excedente do capital, usando-o para atender necessidades sociais. É preciso que nos livremos do problema da acumulação constante dos $3 \%$. Chegamos a um ponto em que uma taxa de crescimento constante de 3\% imporá custos ambientais tão imensos, exercerá uma pressão tão grande sobre as questões sociais, que viveremos em perpétua crise financeira. Se sairmos dessa crise financeira do modo que os capitalistas querem, haverá uma outra crise financeira dentro de cinco anos. Por isso, não podemos mais aceitar o que disse Margaret Thatcher - "não há alternativa”. Devemos, antes, dizer que há uma alternativa. Deve haver uma alternativa para o capitalismo em geral. Podemos começar a nos aproximar dessa alternativa concebendo o direito à cidade como uma exigência popular internacional. Espero que possamos todos nos unir nessa missão. Muito obrigado. 